\title{
Opposite response to hypoxia by breast cancer cells between cell proliferation and cell migration: A clue from microRNA expression profile
}

\author{
MING ZHANG $^{1 *}$, CHANG-E GAO $^{2 *}$, WEN-LIN CHEN $^{3}$, YI-YIN TANG $^{3}$, \\ JIAN-YUN NIE ${ }^{3}$, LI-DA SHEN ${ }^{2}$, XIANG MA $^{4}$ and DE-DIAN CHEN ${ }^{3}$ \\ ${ }^{1}$ Department of Radiation Oncology, The Third Affiliated Hospital of Kunming Medical University, \\ Tumor Hospital of Yunnan, Kunming, Yunnan 650118; ${ }^{2}$ Department of Medical Oncology, The First Affiliated Hospital of \\ Kunming Medical University, Kunming, Yunnan 650032; Departments of ${ }^{3}$ Breast Surgery and ${ }^{4}$ Orthopedics, \\ The Third Affiliated Hospital of Kunming Medical University, Tumor Hospital of Yunnan, \\ Kunming, Yunnan 650118, P.R. China
}

Received November 29, 2015; Accepted May 11, 2017

DOI: $10.3892 / \mathrm{ol} .2017 .7636$

\begin{abstract}
The majority of tumors possess the features of hypoxia. It is generally accepted that hypoxia is a negative prognostic factor for cancer. Low levels of oxygen are able to modify basic cell metabolism status. Elucidating the basic response, including cell proliferation and migration, to hypoxia by cancer cells is important for understanding the role of hypoxia in the development of cancer. In the present study, $\mathrm{CoCl}_{2}$ stimulation was used to simulate hypoxia. A microRNA (miRNA/miR) array was used to systematically detect the changes in miRNA expression profiles. Following treatment with $\mathrm{CoCl}_{2}$ for $12 \mathrm{~h}, 15$ miRNAs were markedly upregulated and 10 miRNAs were markedly decreased compared with the control. After $24 \mathrm{~h} \mathrm{CoCl}_{2}$ incubation, 15 miRNAs were increased and 3 miRNAs were decreased compared with the control. Among them, 7 miRNAs were upregulated and 2 miRNAs were downregulated at 12 and $24 \mathrm{~h}$ following $\mathrm{CoCl}_{2}$ stimulation. The potential roles of these miRNA were reviewed and it was identified that the majority of them are associated with cell proliferation and migration. Additional experiments demonstrated that $\mathrm{CoCl}_{2}$ incubation inhibited the proliferation of MCF-7 cells but promoted cell migration. miR-491 may be a key miRNA for hypoxia-inhibited cell proliferation, as it was identified that hypoxia induced the downregulation of
\end{abstract}

Correspondence to: Professor De-Dian Chen, Department of Breast Surgery, The Third Affiliated Hospital of Kunming Medical University, Tumor Hospital of Yunnan, 191 Renmin West Road, Kunming, Yunnan 650118, P.R. China

E-mail: chendedian2006@hotmail.com

*Contributed equally

Key words: hypoxia, MCF-7, cell proliferation, cell migration, microRNA
B-cell lymphoma-extra large in a miR-491-dependent manner. As the target of miR-302a, CXCR4 may be a key protein for hypoxia-promoted cell migration. In the present study, it was identified that in the early stage of hypoxia, cell proliferation was inhibited but cell migration was promoted. These results support the hypothesis that hypoxia may be a driving force for tumor cell escape from the primary tumor site to other organs, or other sites of the same organ.

\section{Introduction}

Hypoxia is a condition in which the body or a region of the body is deprived of adequate oxygen supply. Tumor hypoxia is the situation where tumor cells have been deprived of enough oxygen. As tumor cells proliferate, the blood is no longer able to supply enough oxygen to the whole tumor. As a result, the oxygen concentration in portions of the tumor cells is significantly lower compared with that in healthy tissues. In order to support continuous growth and proliferation in challenging hypoxic environments, cancer cells have been identified to alter their metabolic pathways, including glucose and glutamine metabolism (1). Due to its contribution to chemoresistance, radioresistance, angiogenesis, vasculogenesis, invasiveness, metastasis, resistance to cell death, altered metabolism and genomic instability, hypoxia is a negative prognostic and predictive factor (2). Due to its central role in tumor progression, studies concerning the basic mechanism by which hypoxia confer to tumor growth and invasion are important. In addition, tumor hypoxia may well be considered the best validated target that has yet to be exploited in oncology.

MicroRNAs (miRNAs/miRs) are the best characterized non-coding RNA family. They have demonstrated fundamental importance in normal development, differentiation, growth control and in human diseases such as cancer (3). On one hand, miRs are involved in the regulation of key cancer-associated pathways, including cell cycle control and DNA damage response. Conversely, due to their important roles in cancer, microRNA molecules are already 
becoming diagnostic and prognostic biomarkers for patient stratification and therapeutic targets and agents (4). The microRNAs involved in hypoxia have also been studied (5) and identified to be involved in the regulation of expression of hypoxia-inducible factor $1-\alpha$ (HIF-1 $\alpha$ ).

Although hypoxia and miRs in tumors have been extensively investigated, the early stage and acute hypoxia-induced tumor cell miR expression profile has not yet been examined, to the best of our knowledge. The early stages of hypoxia may reflect how tumor cells cope with the microenvironments with insufficient oxygen. The addition of hypoxia mimics such as cobalt (II) chloride to the culturing medium are able to simulate this condition. The present study sought to investigate the changes in miR expression profiles in MCF-7 cells subsequent to cobalt (II) chloride stimulation, and the association between these miRs and changes in cell behavior, including changes in cell growth and migration. The experiments from the present study demonstrated that the early stage and acute hypoxia simulated by cobalt (II) chloride was able to inhibit the cell growth, but concurrently promote cell migration dependent on different miRs. This is concordant with the hypothesis that one of the strategies for tumor cells, when faced with hypoxia, is to escape from the primary tumor site, which results in metastatic tumors.

\section{Materials and methods}

Cell culture and transfection. Human breast cancer cell lines, including low invasive $\mathrm{MCF}-7$ and high invasive MDA-MB-231 cell lines were obtained from Kunming Cell Bank, Chinese Academy of Sciences (Yunnan, China), and cultured in Dulbecco's modified Eagle's medium (DMEM; Hyclone; GE Healthcare Life Sciences, Logan, UT, USA) supplemented with $10 \%$ fetal bovine serum (Hyclone; GE Healthcare Life Sciences, Logan, UT, USA), 100 U/ml penicillin (Sigma-Aldrich; Merck KGaA, Darmstadt, Germany), $100 \mu \mathrm{g} / \mathrm{ml}$ streptomycin (Sigma-Aldrich; Merck KGaA), and 2 mM L-glutamine (Gibco; Thermo Fisher Scientific, Inc., Waltham, MA, USA) at $37^{\circ} \mathrm{C}$ in a humidified atmosphere of $5 \% \mathrm{CO}_{2}$. The non-invasive human breast epithelial MCF-10A cell line was obtained from Shanghai Cell Bank, Chinese Academy of Sciences, and was cultured in DMEM:F12 (1:1) (Hyclone; GE Healthcare Life Science) medium supplemented with 5\% horse serum (Hyclone; GE Healthcare Life Sciences), $10 \mu \mathrm{g} / \mathrm{ml}$ insulin (Gibco; Thermo Fisher Scientific, Inc.), $20 \mathrm{ng} / \mathrm{ml}$ epidermal growth factor (Gibco; Thermo Fisher Scientific, Inc.), $100 \mathrm{ng} / \mathrm{ml}$ cholera toxin (Sigma-Aldrich; Merck KGaA) and $0.5 \mu \mathrm{g} / \mathrm{ml}$ hydrocortisone (Sigma-Aldrich; Merck KGaA).

Transfection of cells was performed using Lipofectamine $2000^{\circledR}$ (Invitrogen; Thermo Fisher Scientific, Inc.) as previously described (6). miR-491 inhibitor, miR inhibitor negative control, miR-302a mimic and miR control were purchased from Guangzhou RiboBio Co. Ltd (Guangzhou, China).

All other chemicals were purchased from Sigma-Aldrich (Merck KGaA).

Cytotoxicity assay. Cytotoxicity was measured by the MTT method as previously described (7) and five repeats were performed for each sample. Exponentially growing cells were seeded at $5 \times 10^{3}$ cells/well in a 96 -well microplate that was supplemented with $200 \mu 1$ serum-free DMEM/F12. Following overnight growth, the cells were exposed to various concentrations $(50-1,600 \mu \mathrm{g} / \mathrm{ml})$ of cobalt chloride $\left(\mathrm{CoCl}_{2}\right.$; Sigma-Aldrich; Merck KGaA). Distilled water was used to dissolve $\mathrm{CoCl}_{2}$. Subsequent to incubation at $37^{\circ} \mathrm{C}$ of the treated cells for $24 \mathrm{~h}, 20 \mu \mathrm{l} \mathrm{MTT}(5 \mathrm{mg} / \mathrm{ml}$; Sigma-Aldrich; Merck $\mathrm{KGaA}$ ) was added and the plates were incubated at $37^{\circ} \mathrm{C}$ for $4 \mathrm{~h}$. Then, the supernatants were carefully removed and $100 \mu \mathrm{l}$ dimethyl sulfoxide was added to dissolve the formazan. The plates were measured at $570 \mathrm{~nm}$ by an Infinite 200 spectrometer (Tecan Trading Co., Ltd., Shanghai, China). The $\mathrm{IC}_{50}$ value was determined by plotting the drug concentration vs. the survival ratio of the treated cells.

miRNA array. Total RNA from $\mathrm{CoCl}_{2}$-treated or untreated MCF-7 cells, including miRNA, was extracted using TRIzol reagent (Invitrogen; Thermo Fisher Scientific, Inc.). The quality and integrity of total RNA was assessed with Agilent 2100 Bioanalyzer (Agilent Technologies, Inc., Santa Clara, CA, USA). Small RNA was enriched using the mirVana ${ }^{\mathrm{TM}}$ miRNA Isolation kit (Applied Biosystems; Thermo Fisher Scientific, Inc.) according to the manufacturer's protocol. The isolated RNA was converted to complementary DNA (cDNA) using human miRNA primer pools A \& B respectively (Applied Biosystems; Thermo Fisher Scientific, Inc.) and the cDNA was used to run the quantitative reaction in 2 human miRNA Taqman low density arrays (TLDA ABI cards version 2.0) on a 7900HT real time PCR machine (Applied Biosystems; Thermo Fisher Scientific, Inc.). The thermocycling conditions were as follows: $95^{\circ} \mathrm{C}$ for $3 \mathrm{~min}$ followed by 45 cycles of $95^{\circ} \mathrm{C}$ for $10 \mathrm{sec}$ and $60^{\circ} \mathrm{C}$ for $20 \mathrm{sec}$. The data was imported into the StatMiner ${ }^{\circledR}$ V5.0 software (Integromics, Granada, Spain) and analyzed using the default settings. The appropriate protocols were used to validate certain reactions in single-tube reaction mixes to verify expression of miRNA (Applied Biosystems protocol. Part No 4364031, Rev C 12/2009) (8). The experiment was performed two times.

Cell proliferation assay. The MCF-7 cells were seeded on a 96-well plate (1,000 cells/well), and $24 \mathrm{~h}$ following seeding, fresh medium supplemented with $10 \%$ FBS containing different concentrations $(50-800 \mu \mathrm{M})$ of $\mathrm{CoCl}_{2}$ was added into the plates and changed every $24 \mathrm{~h}$. The number of viable cells was estimated by the MTT method every $24 \mathrm{~h}$ (9).

Cell migration assay. Cell migration was tested with a Boyden chamber assay, which was performed with 24-well plates (Corning Incorporated, Corning, NY, USA) and Transwell ( $8 \mu \mathrm{m}$ pore; Merck KGaA) (10). The bottom side of the Transwell plates was coated with collagen type I (10 $\mu \mathrm{g} / \mathrm{ml}$; Sigma-Aldrich; Merck KGaA). Following starvation for $12 \mathrm{~h}$ with starvation medium (DMEM/F12) containing $0.25 \%$ bovine serum albumin (BSA; Sigma-Aldrich; Merck $\mathrm{KGaA}$ ), the cells were detached with cell dissociation buffer (Sigma-Aldrich; Merck KGaA), then $1 \times 10^{5}$ cells were planted into the top of each chamber. Media containing 1\% FBS were added into the bottom of the chamber for $16 \mathrm{~h}$. Migrated cells were dyed with crystal violet $(0.1 \%$ in $0.1 \mathrm{M}$ borate buffer solution, $\mathrm{pH} 8.5$ ) for $20 \mathrm{~min}$. Bound crystal violet was eluted with 
A

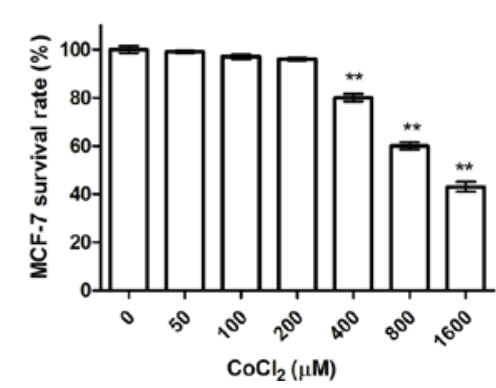

B

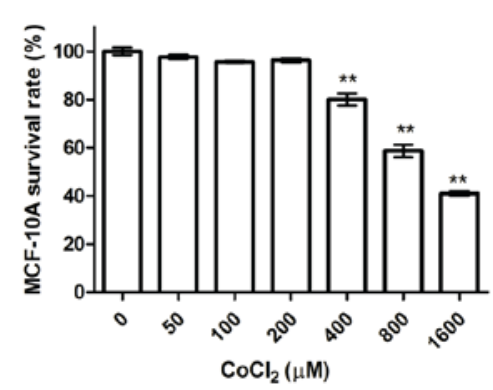

C

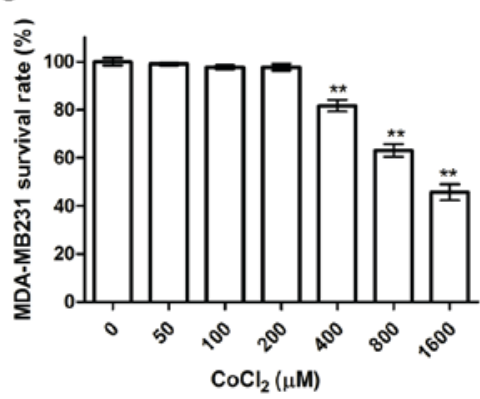

Figure 1. Toxicity of $\mathrm{CoCl}_{2}$ in MCF-7, MCF-10A and MDA-MB-231 cells. (A) MCF-7, (B) MCF-10A and (C) MDA-MB-231 cells were incubated with $50-1,600 \mu \mathrm{M} \mathrm{CoCl}_{2}$ for $24 \mathrm{~h}$, followed by an MTT assay to assess the cell survival rate. The survival rate was calculated according to the optical density at $570 \mathrm{~nm} .{ }^{* *} \mathrm{P}<0.01$ compared with the ' 0 ' group.

$1 \mathrm{ml} \mathrm{10 \%} \mathrm{acetic} \mathrm{acid} \mathrm{and} \mathrm{the} \mathrm{migration} \mathrm{activity} \mathrm{was} \mathrm{expressed}$ as the value monitored at $586 \mathrm{~nm}$ of extraction.

Western blotting. Following different stimulations, including $\mathrm{CoCl}_{2}$ incubation, miRNA or miRNA inhibitor transfection, the MCF-7 cells were then collected, washed, and immediately lysed on ice in lysis buffer containing $50 \mathrm{mM}$ HEPES (pH 7.4), $5 \mathrm{mM}$ EDTA, $50 \mathrm{mM} \mathrm{NaCl}, 1 \%$ Triton $\mathrm{X}-100$, $50 \mathrm{mM}$ NaF, $5 \mathrm{mg} / \mathrm{ml}$ aprotinin, $5 \mathrm{mg} / \mathrm{ml}$ leupeptin and $1 \mathrm{mM}$ phenylmethylsulfonyl fluoride. The proteins $(30 \mu \mathrm{g})$ were electrophoresed on 12\% SDS-PAGE and transferred onto polyvinylidene fluoride membranes. The membranes were subsequently blocked at $4^{\circ} \mathrm{C}$ overnight with $3 \%$ BSA and incubated at room temperature for $4 \mathrm{~h}$ with the appropriate primary and at room temperature for $2 \mathrm{~h}$ with secondary antibodies. The protein bands were visualized with Super Signal chemiluminescence reagents (Pierce; Thermo Fisher Scientific, Inc.), as previously described (11). The antibodies used in the present study were purchased from Santa Cruz Biotechnology, Inc. (Dallas, TX, USA). The target genes of selected miRNA, including miR-491 and miR-302a, were Bcl-xL and CXCR4 as previously reported $(12,13)$. The antibodies were as follows: Rabbit polyclonal antibody against human Bcl-xL (cat. no. sc-7195; dilution, 1:1,000); mouse monoclonal antibody against human CXCR4 (cat. no. sc-53534; dilution, 1:1,000); rabbit polyclonal antibody against human $\beta$-actin (cat. no. sc-7210; dilution, 1:2,000); mouse monoclonal antibody against ERK2 (cat. no. sc-1647; dilution, 1:1,000); mouse monoclonal antibody against human phospho-ERK1/2 (cat. no. sc-7383; dilution, 1:1,000); goat anti-mouse IgG-HRP (cat. no. sc-2005; dilution, 1:5,000); goat anti-rabbit IgG-HRP (cat. no. sc-2004; dilution, 1:5,000).

Statistical analysis. The data were analyzed with unpaired Student's t-test for variance. Experimental values expressed as the mean \pm standard deviation. $\mathrm{P}<0.05$ was considered to indicate a statistically significant difference.

\section{Results}

$\mathrm{CoCl}_{2}$ demonstrates toxicity to MCF-7, MCF-10A and $M D A-M B-231$ in a dose-dependent manner. In vitro cytotoxicity of $\mathrm{CoCl}_{2}$ in the normal breast epithelial MCF-10A cell line and breast cancer low invasive MCF-7 and high invasive
MDA-MB231 cell lines were examined. Exponentially growing cells were incubated with various concentrations of $\mathrm{CoCl}_{2}$. Following $24 \mathrm{~h}$ incubation, the cytotoxic activity was evaluated by the MTT assay. The half-maximal inhibitory concentration $\left(\mathrm{IC}_{50}\right)$ was calculated for cobalt chloride. The $\mathrm{CoCl}_{2}$ demonstrated cell toxicity in a dose-dependent manner (Fig. 1). The $\mathrm{IC}_{50}$ value of $\mathrm{CoCl}_{2}$ to $\mathrm{MCF}-7, \mathrm{MCF}-10 \mathrm{~A}$ and MDA-MB-231 cells were 1,257, 1,216 and 1,331 $\mu \mathrm{M}$, respectively. No significant differences in cell survival rate were identified between the cells treated with 50, 100 and $200 \mu \mathrm{M}$ of $\mathrm{CoCl}_{2}$ in all the 3 cell lines tested. Furthermore, no significant differences in cytotoxicity were identified between MCF-7, MCF-10 and MDA-MB-231 cells in response to $\mathrm{CoCl}_{2}$ stimulation.

$\mathrm{CoCl}_{2}$ alters the miRNA expression profile of $\mathrm{MCF}-7$ cells. miRs regulate numerous intracellular process by affecting gene expression. Thus, the changes to miRs expression may, to a large extent, reflect what happens to the cells. In the present study, the cells were incubated with $\mathrm{CoCl}_{2}$ at a concentration of $200 \mu \mathrm{M}$ for 0,12 or $24 \mathrm{~h}$. Then, miRNA expression profiles were detected by TLDA on a 7900HT real time PCR machine. At this concentration, $\mathrm{CoCl}_{2}$ demonstrated no acute cytotoxicity to the cells. $\mathrm{CoCl}_{2}$ induced significant upregulation of 15 miRNAs and downregulation of 10 miRNAs (Table I) following $12 \mathrm{~h}$ incubation with MCF-7 cells. However, following $24 \mathrm{~h}$ incubation, 15 miRNAs were upregulated and only 3 were downregulated (Table I). Among these miRNAs, 7 miRNAs were continuously upregulated 12 and $24 \mathrm{~h}$ following incubation with $\mathrm{CoCl}_{2}$, and 2 miRNAs were downregulated (Table III). These miRNAs are associated with basic cell processes, including cell proliferation and cell migration (Table IV). The majority of these upregulated miRNAs appear to have the ability to suppress cell proliferation. However, their role in cell migration remains ambiguous. The downregulated miRNAs have potent abilities to inhibit cell proliferation and cell migration.

$\mathrm{CoCl}_{2}$ simulates hypoxia-inhibited cell growth but promotes cell motility. Previous studies have demonstrated that $\mathrm{CoCl}_{2}$ stimulation may inhibit the cell proliferation $(14,15)$. However, other studies have suggested that $\mathrm{CoCl}_{2}$-mimicked hypoxia may promote cell migration (16). The effects of $\mathrm{CoCl}_{2}$ on the proliferation and migration in the $\mathrm{MCF}-7$ cell line remain 


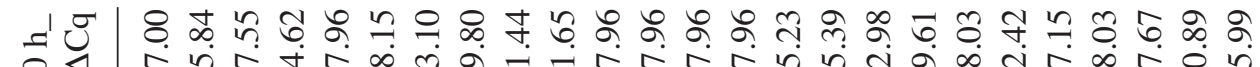

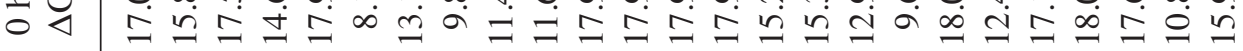
క⿱一兀

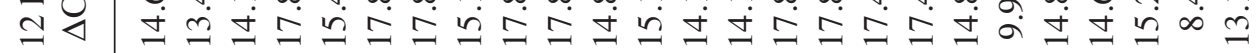

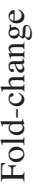

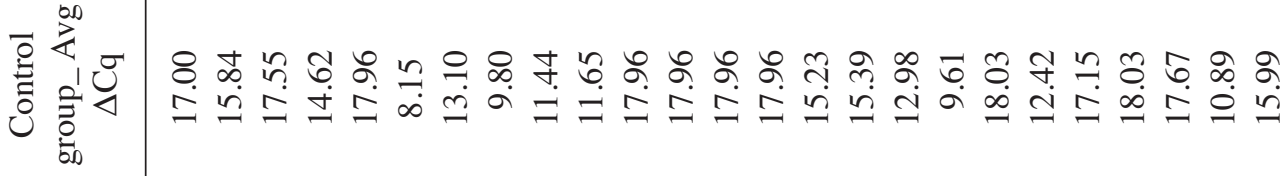

స్తే

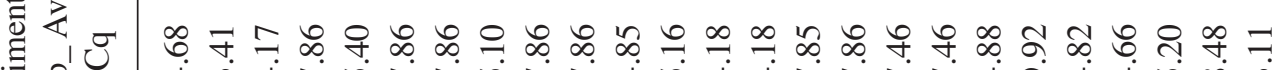

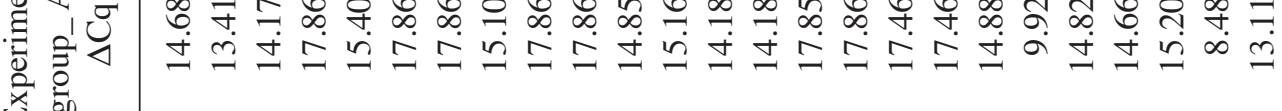
近

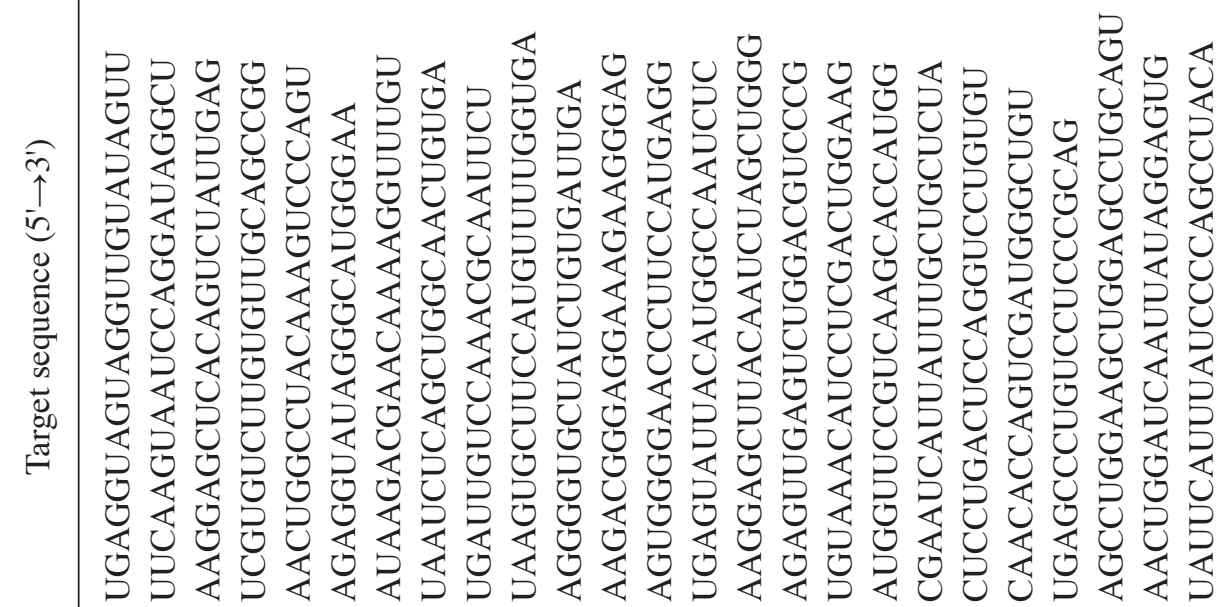

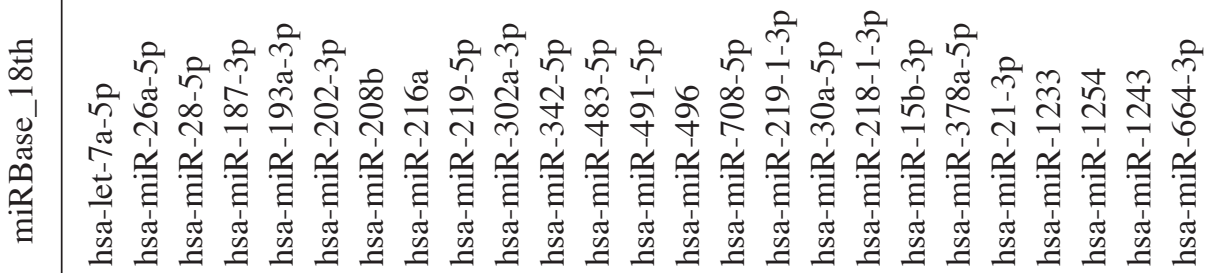

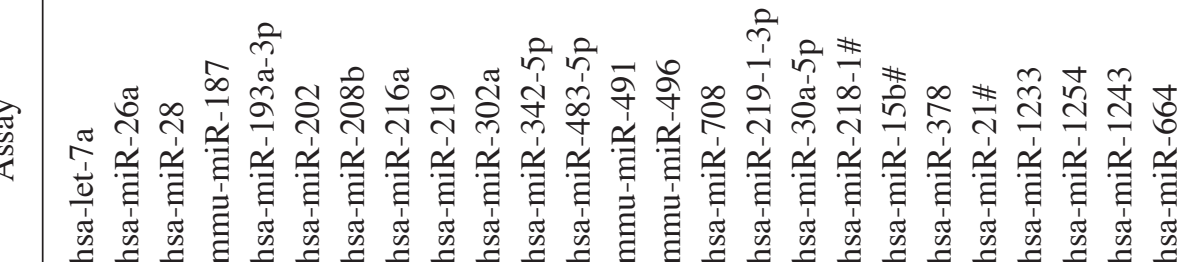

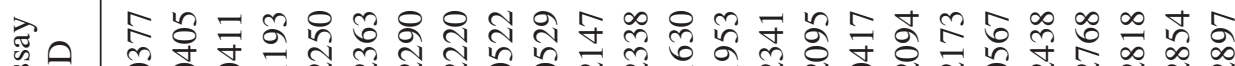
娄 :

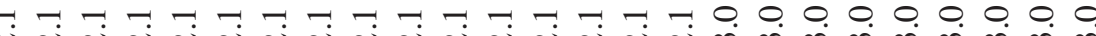

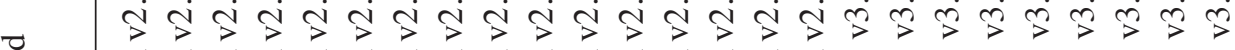

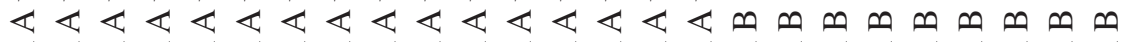




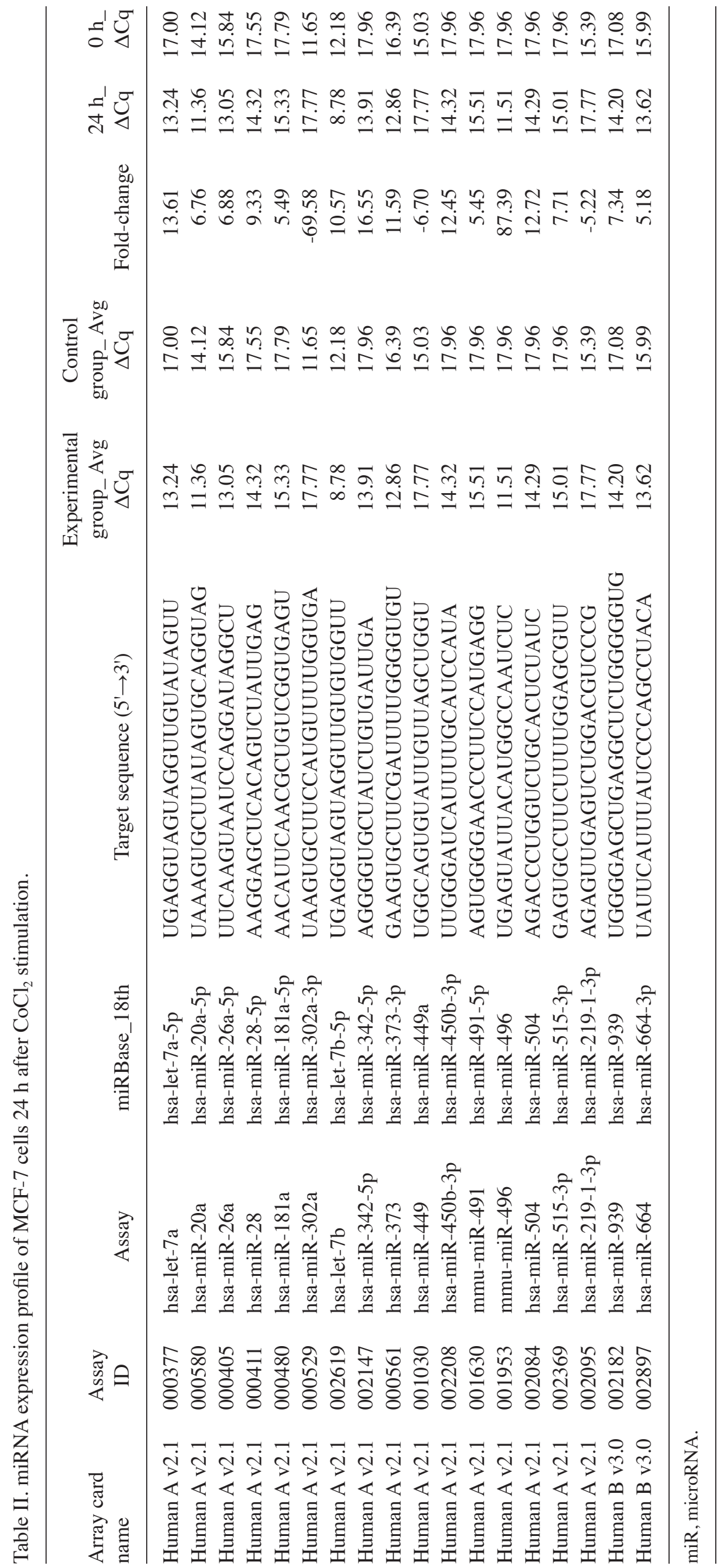


Table III. Summary of upregulated and downregulated miRNAs.

\begin{tabular}{lcc}
\hline miRNA & $\log _{2}($ Fold $)(12 \mathrm{~h})$ & $\log _{2}($ Fold $)(24 \mathrm{~h})$ \\
\hline let-7a & 5.00 & 13.61 \\
miR-26a & 5.37 & 6.88 \\
miR-28 & 10.35 & 9.33 \\
miR-302a & -74.05 & -69.58 \\
miR-342-5p & 8.64 & 16.55 \\
miR-491 & 13.68 & 5.45 \\
miR-496 & 13.67 & 87.39 \\
miR-219-1-3p & -5.56 & -5.22 \\
miR-664 & 7.35 & 5.18 \\
\hline
\end{tabular}

miRNA, microRNA.

unclear. In the present study, $\mathrm{MCF}-7$ cells were treated with different concentration of $\mathrm{CoCl}_{2}$ and the cell viability were assessed by MTT assay. The results demonstrated that $\mathrm{CoCl}_{2}$ inhibited cell growth of MCF-7 in a dose-dependent manner (Fig. 2A). Conversely, $\mathrm{CoCl}_{2}$ promoted cell migration of MCF-7 in a dose-dependent manner between the dose of 50 and $400 \mu \mathrm{M}$ (all $\mathrm{P}<0.01$; Fig. 2B).

miR-491 is involved in $\mathrm{CoCl}_{2}$ inhibited cell growth and miR-302a is involved in $\mathrm{CoCl}_{2}$-promoted cell migration. As aforementioned, it is notable that $\mathrm{CoCl}_{2}$ may inhibit cell growth, yet concomitantly promote cell migration. The miRNA profile is an important clue to explain this occurrence. As summarized in Table IV, these altered miRNAs are associated with cell growth and cell migration. Thus, two miRNAs, miR-491 and miR-302a, were selected for in-depth investigation.

miR-491 is significantly upregulated at 12 and $24 \mathrm{~h}$ following incubation with $\mathrm{CoCl}_{2}$, and it was previously identified to be involved in the inhibition of cell proliferation (17). Therefore, it may serve a significant role in $\mathrm{CoCl}_{2}$-inhibited cell growth. The has-miR-491-5p inhibitor was transfected into MCF-7 cells to attenuate the upregulated level of miR-491 by $\mathrm{CoCl}_{2}$. The rates of cell growth and cell migration were assessed, and the results demonstrated that the miR-491-5p inhibitor significantly attenuated $\mathrm{CoCl}_{2}$ inhibition on MCF-7 cell growth $(\mathrm{P}<0.05$; Fig. $3 \mathrm{~A})$ but exhibited no significant effects on cell migration (Fig. 3B).

miR-302a was the most downregulated miRNA following $\mathrm{CoCl}_{2}$ treatment. miR-302a mimics were transfected into MCF-7 cells to rescue the miR-302a downregulated by $\mathrm{CoCl}_{2}$. Then, the rates of cell growth and cell migration were assessed. The results indicated that miR-302a mimics did not exhibit a significant effect on cell proliferation (Fig. 3C), but they did significantly reduce $\mathrm{CoCl}_{2}$-enhanced cell migration $(\mathrm{P}<0.05$; Fig. 3D).

$\mathrm{CoCl}_{2}$ stimulated changes in the expression of numerous miRNAs, yet their roles in the modification of cell growth and migration in $\mathrm{CoCl}_{2}$-simulated hypoxia requires additional study. However, it is clear that miR-491 is involved in
Table IV. Potential role of the miRNAs in cell proliferation, migration and invasion.

\begin{tabular}{lll}
\hline miRNA & \multicolumn{1}{c}{ Proliferation } & $\begin{array}{c}\text { Migration and } \\
\text { invasion }\end{array}$ \\
\hline $\begin{array}{l}\text { Upregulated } \\
\text { let-7a }\end{array}$ & A549 $\downarrow(31)$, PC3 $\downarrow$ (32) & HepG2 $\downarrow$ (33) \\
miR-26a & MHCC-79L $\downarrow(34)$, & A549 $\downarrow(36)$ \\
miR-28 & DU145 $\uparrow(35)$ & \\
miR-342-5p & HCT116 $\downarrow(37)$ & HCT116 $\downarrow$ (37) $\downarrow$ (38) \\
miR-491 & U251 $\downarrow(17)$ & ND \\
miR-496 & ND & ND \\
miR-664 & A375 $\downarrow(39)$ & ND \\
Downregulated & & ND \\
miR-302a & ND & \\
miR-219-1-3p & PDAC-derived & PDAC-derived \\
& cell lines $\downarrow(40)$ & cell lines $\downarrow(40)$
\end{tabular}

miRNA, microRNA; $\uparrow$, upregulation; $\downarrow$, downregulation; ND, not defined; PDAC, pancreatic ductal adenocarcinoma.

$\mathrm{CoCl}_{2}$-induced inhibition of cell growth, and that miR-302a is involved in $\mathrm{CoCl}_{2}$-induced promotion of cell migration.

miR-491 regulates the expression of $B$-cell lymphoma-extra large $(B c l-x L)$. The aforementioned experiments demonstrated that miR-491 serves an important role in $\mathrm{CoCl}_{2}$-induced inhibition of cell proliferation. It has been identified that miR-491 may target $\mathrm{Bcl}-\mathrm{xL}$, thus inducing apoptosis and inhibiting cell proliferation (18). Western blot analysis demonstrated a marked decrease in Bcl-xL expression following treatment with $\mathrm{CoCl}_{2}$ compared with the control; however, treatment with miR-491 inhibitors rescued this effect (Fig. 4A).

miR-302a regulates the expression of $C-X-C$ chemokine receptor 4 (CXCR4). miR-302a affected the $\mathrm{CoCl}_{2}$-induced promotion of cell migration. The specific target gene and its mechanism of action require additional study. It has been previously revealed that CXCR4 is the target of miR-302a $(12,13)$. In the present study, it was identified that $\mathrm{CoCl}_{2}$ markedly upregulates the level of CXCR4 (Fig. 4B); however, transfection with miR-302a mimics attenuated the $\mathrm{CoCl}_{2}$-induced upregulation of CXCR4. This suggested that miR-302a may affect cell migration in the MCF-7 cell line, at least partially by targeting CXCR4.

miR-491 upregulation and miR-302a downregulation mediate extracellular signal-related kinase (ERK)1/2 activation by $\mathrm{CoCl}_{2} \cdot \mathrm{CoCl}_{2}$ stimulation markedly induced the phosphorylation of ERK1/2 (Fig. 5A), which is consistent with the results from a previous study (19). To investigate the potential role of miR-491 in $\mathrm{CoCl}_{2}$-induced ERK1/2 activation, miR-491 inhibitors were transfected into MCF-7 cells, and it was identified that inhibition may moderately attenuate $\mathrm{CoCl}_{2}$-induced ERK1/2 activation, which was consistent with a previous 
A

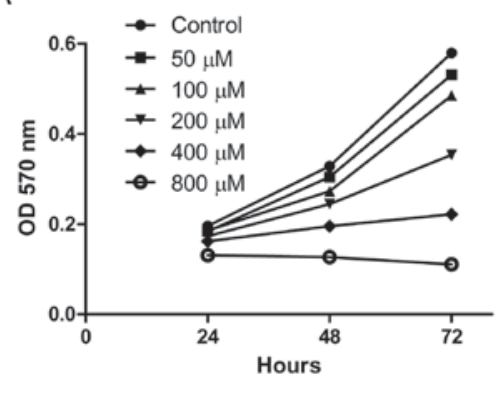

B

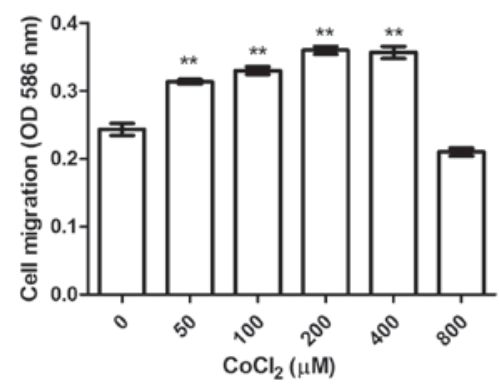

Figure 2. $\mathrm{CoCl}_{2}$-simulated hypoxia inhibited cell growth but promoted cell motility. (A) Cells were incubated with different concentrations of CoCl $\mathrm{C}_{2}$ Cell viability was assessed by MTT assay. (B) Cells were first starved with serum-free medium for $12 \mathrm{~h}$, and then pretreated with different concentrations of $\mathrm{CoCl}_{2}$ for $12 \mathrm{~h}$. Cell migration was assessed by Transwell assay. ${ }^{* *} \mathrm{P}<0.01$ compared with the '0' group. ns, not significant; OD, optical density.

A

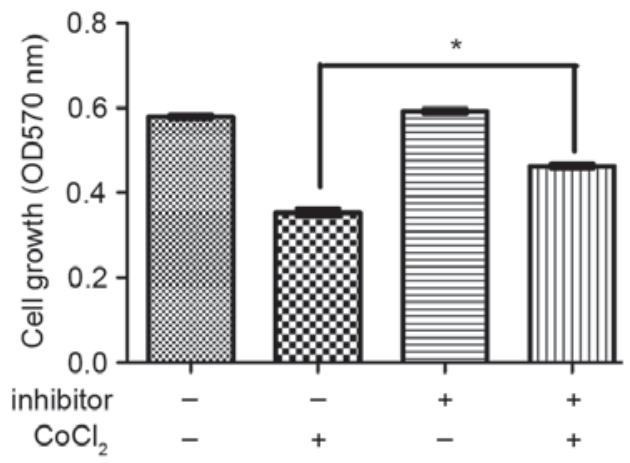

C

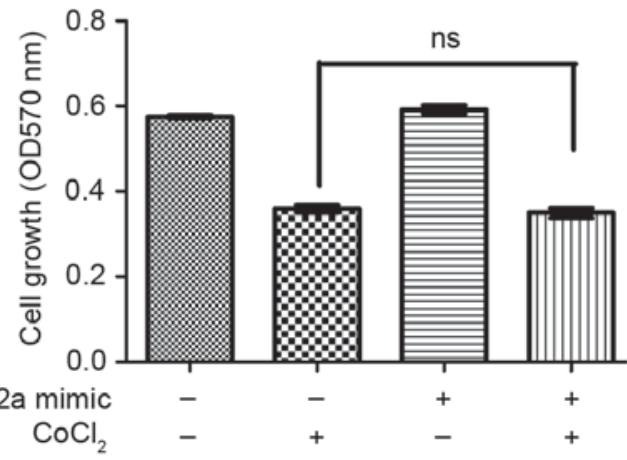

B

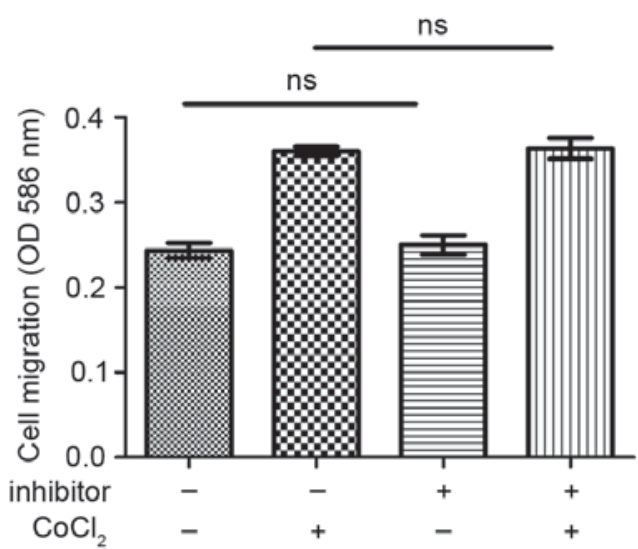

D

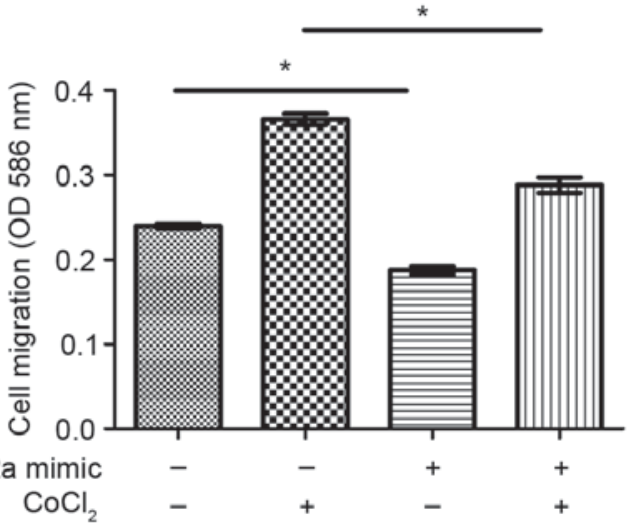

Figure 3. miR-491 is involved in $\mathrm{CoCl}_{2}$ inhibited cell growth and miR-302a is involved in $\mathrm{CoCl}_{2}$ promoted cell migration. (A) $\mathrm{MCF}-7$ cells were transfected with a miR-491-5p inhibitor (+) or negative control (-). Following $18 \mathrm{~h}$ of transfection, cells were seeded onto $96-$ well plates. After $18 \mathrm{~h}$ seeding, cells were incubated with or without $\mathrm{CoCl}_{2}$ for $72 \mathrm{~h}$. Then, cell viability was assessed by MTT assay. (B) MCF-7 cells were transfected with a miR-491-5p inhibitor (+) or negative control (-). Cells were first starved with serum-free medium for $12 \mathrm{~h}$, and then pretreated with $200 \mu \mathrm{M}$ of CoCl${ }_{2}$ for $12 \mathrm{~h}$. Cell migration was assessed by Transwell assay as aforementioned. (C) MCF-7 cells were transfected with miR-302a mimics (+) or control miRNA (-). Cell proliferation was assessed in the same way as in (A). (D) MCF-7 cells were transfected with miR-302a mimics (+) or control miRNA (-). Cell migration was assessed the same way as in (B). ns, not significant, $\mathrm{P}>0.05 ;{ }^{*} \mathrm{P}<0.05$; miR, microRNA; OD, optical density.

result (20). The present study also examined the role of miR-302a in ERK1/2 activation, and it was revealed that transfection of miR-302a mimic also resulted in the attenuation of ERK1/2 activation (Fig. 5B). ERK1/2 may be involved in the modification of cell proliferation and cell migration in hypoxia, but it requires additional study.

\section{Discussion}

Hypoxia is involved in numerous physiological and pathological processes. During previous in vitro studies, a number of chemicals have been used to mimic hypoxia (21). $\mathrm{CoCl}_{2}$ is the most frequently used hypoxia mimic. Hypoxia is associated with 


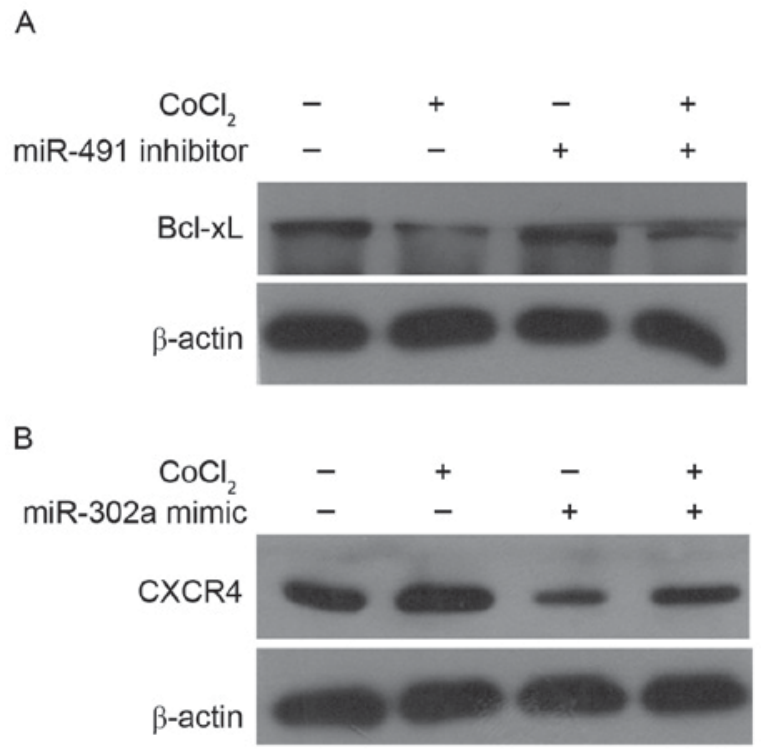

Figure 4. miR-491 targeted Bcl-xL and miR-302a targeted CXCR4, respectively, to modify cell growth and cell migration. (A) MCF-7 cells were transfected with miR-491-5p inhibitors (+) or negative control (-). After $24 \mathrm{~h}$ transfection, cells were incubated with or without $\mathrm{CoCl}_{2}$ for $48 \mathrm{~h}$. Then, the cells were harvested for western blot analysis as aforementioned. (B) MCF-7 cells were transfected with miR-302a mimics (+) or negative control (-). After $24 \mathrm{~h}$ transfection, cells were incubated with or without $\mathrm{CoCl}_{2}$ for $48 \mathrm{~h}$. Then, the cells were harvested for western blot analysis as aforementioned. Bcl-xL, B-cell lymphoma-extra large; CXCR4, C-X-C chemokine receptor 4; miR, microRNA.
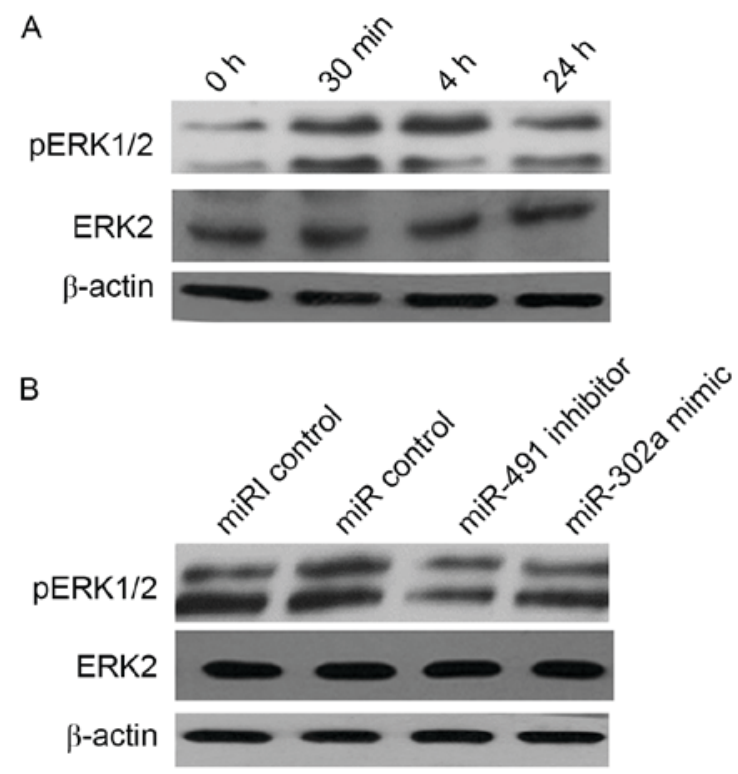

Figure 5. miR-491 and miR-302a were involved in $\mathrm{CoCl}_{2}$ induced ERK1/2 activation. (A) MCF-7 cells were stimulated with $\mathrm{CoCl}_{2}$ for $30 \mathrm{~min}, 4$ or $24 \mathrm{~h}$, and then the cells were lysed for the detection of phosphor-ERK1/2 (pERK1/2) by western blot analysis. The total ERK1/2 and $\beta$-actin were also detected. (B) For assessing the role of miR-491 and miR-302a, miR-491 inhibitors or miR-302a mimics were transfected $36 \mathrm{~h}$ prior to $\mathrm{CoCl}_{2}$ stimulation. Then. the levels of p-ERK1/2 were assessed by western blotting. miR, microRNA; pERK1/2, phosphor-ERK1/2.

tumor growth (22) and metastasis (23). Numerous studies have focused on identifying the role of hypoxia in cancer occurrence and its involved mechanisms. Hypoxic conditions arise

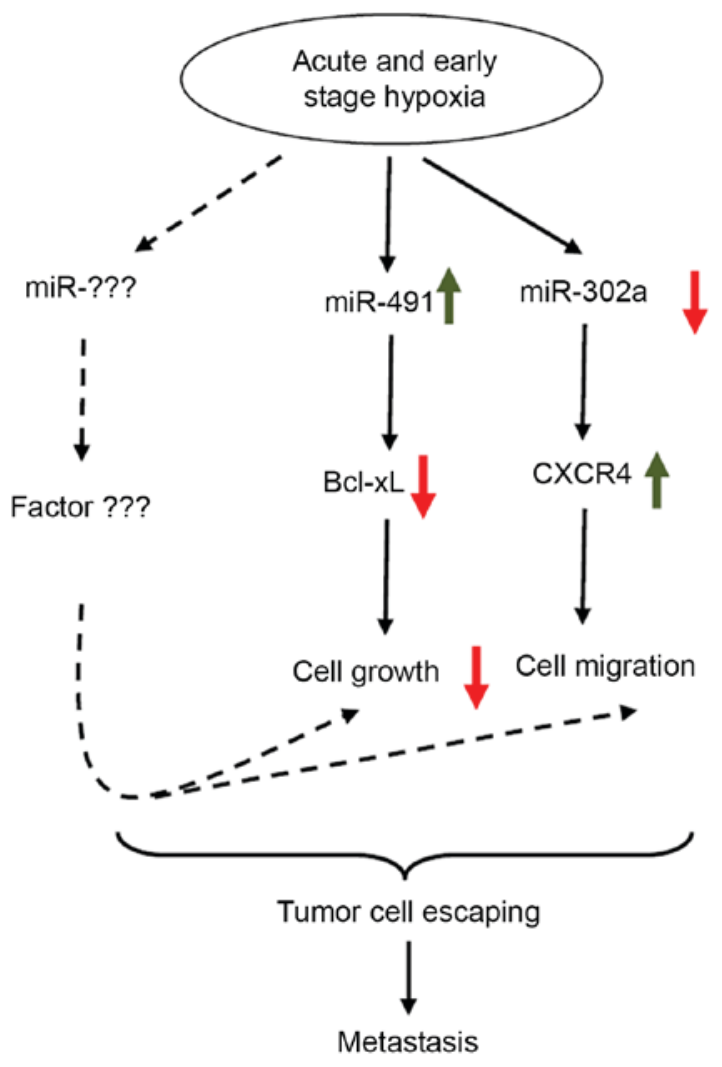

Figure 6. Proposed mechanism by miR-491 and miR-302a to modify tumor cell behavior. miR, microRNA; Bcl-xL, B-cell lymphoma-extra large; CXCR4, C-X-C chemokine receptor 4.

due to the high rate of tumor cell proliferation and solid tumor formation. During the early stage of solid tumor formation, the tumor cells must become accustomed to hypoxic conditions. In in vitro models, the addition of hypoxia mimic chemicals, including $\mathrm{CoCl}_{2}$ to the culturing medium may simulate the cellular response during the early stage of tumor growth. The present study aimed to identify what occurred to the cells during this stage.

miRNAs serve a pivotal role in tumor biology. Certain miRNAs may act as tumor suppressors or oncogenes (24). These miRNAs affect tumor growth and metastasis by targeting tumor associated protein-encoding genes. In the present study, miRNA profiles were analyzed by miRNA array. The altered miRNAs were associated with cell proliferation and cell migration, which may be important for tumor cells. Additional study of the detailed roles of these miRNAs is important for understanding $\mathrm{CoCl}_{2}$-simulated hypoxia in basic tumor cell biology, including cell proliferation and cell migration. In the present study, 2 markedly upregulated or downregulated miRNAs, miR-491 and miR-302a, were selected for investigation concerning their targets and their roles in cell growth and cell migration.

It was identified that miR-491 attenuated $\mathrm{CoCl}_{2}$-induced inhibition of cell growth. This may be attributed to the downregulated level of Bcl-xL by miR-491. Previous studies revealed that miR-491 may target various genes including $B c l-x L$ and G-protein-coupled receptor kinase-interacting protein 1 (GITl) (13,20). Bcl-xL downregulation may promote cell apoptosis and inhibit cell proliferation (18), and the 
downregulation of GIT1 may inhibit cell migration (20). Hypothetically, upregulation of miR-491 will induce the downregulation of GIT1, thus inhibiting cell migration. However, $\mathrm{CoCl}_{2}$ did not inhibit cell migration, which meant that the inhibition of cell migration induced by miR-491/GIT1 was masked by other altered genes. Of all the upregulated and downregulated miRNAs, miR-302a was the most downregulated. CXCR4 has been indicated to be the target of miR-302a (12). CXCR4 is an $\alpha$-chemokine receptor specific for stromal cell-derived factor 1 (SDF-1), a molecule with potent chemotactic activity for lymphocytes. The expression of CXCR4 in healthy tissues is low or absent, however, it is expressed in a number of types of cancer, including breast cancer, melanoma and ovarian cancer (25). CXCR4 expression is associated with metastasis to tissues containing a high concentration of SDF-1, including lungs, liver and bone marrow (26). In the present study, $\mathrm{CoCl}_{2}$-stimulated hypoxia significantly upregulated the expression of CXCR4 by lowering the miR-302a level. This is consistent with a previous study, which demonstrated that hypoxia may drive the metastasis of tumors (23).

Numerous studies have suggested that hypoxia may encourage tumor growth (22), partially mediated by HIF-1 $\alpha$ (27). However; at the early stage of tumor cell growth, uncontrolled cell proliferation results in a lack of oxygen supply in the cells, that is, hypoxia. Logically, there are two ways for cells to manage this: i) to adjust their metabolic pathways to be accustomed to the low oxygen supply; ii) to escape from hypoxic environment, or metastasize. At the early stage of tumor growth, concomitant with the results from the present study, cell proliferation may be markedly affected by the lack of oxygen supply (28). Yet, the migration ability of these cells is markedly elevated, and this is partially mediated by CXCR4 (Fig. 6). Previous studies have been focused on the role of mitogen-activated protein kinases, including ERK1/2, in tumor cell proliferation and migration (29). It was identified that the activation of ERK1/2 generally promotes cell survival, but under certain conditions, ERK1/2 may have apoptotic functions (30). In the present study, the $\mathrm{CoCl}_{2}$-induced activation of ERK/1/2 may be viewed as the cell response to the $\mathrm{CoCl}_{2}$-induced hypoxia to promote cell survival. However, the role of miR-491 and miR-302a in the activation of ERK1/2 may be complicated, and requires additional investigation. Future experiments are required to explore the signal cascade involved in the hypoxia-induced inhibition of cell proliferation and promotion of migration.

Although it has been shown that hypoxia can promote tumor cell growth when cell proliferation of MCF-7 cells is inhibited, this has not been demonstrated in other cell types. Additional in-depth in vitro and in vivo experiments focused on other types of cell line are required to strengthen this hypothesis. In addition, understanding the association between the oxygen concentration of the original tumor tissue, and the rates of tumor metastasis, will also provide important evidence for this hypothesis. The different miRNA expression profiles between breast tumor and normal tissues, and also between different sites of the tumor tissues, will provide important information. In conclusion, the present study revealed that acute hypoxia may inhibit MCF-7 cell proliferation by miR-491/Bcl-xL upregulation. Conversely, the rate of cell migration was increased by $\mathrm{CXCR} 4$ upregulation. These results may partially demonstrate what occurs during the early stages of hypoxia. Additional clinical investigation is required to confirm these data.

\section{Acknowledgements}

The present study was supported by the National Science Foundation of Yunnan Province (grant no. 2011FB206). This study was financed by The Joint Special Funds For The Department Of Science \& Technology Of Yunnan Province Kunming Medical University [grant nos. 2017FE467 (-190) and 2017FE468 (-199)].

\section{References}

1. Boroughs LK and DeBerardinis RJ: Metabolic pathways promoting cancer cell survival and growth. Nat Cell Biol 17: 351-359, 2015.

2. Wilson WR and Hay MP: Targeting hypoxia in cancer therapy. Nat Rev Cancer 11: 393-410, 2011.

3. Jansson MD and Lund AH: MicroRNA and cancer. Mol Oncol 6: 590-610, 2012 .

4. Ling H, Fabbri $M$ and Calin GA: MicroRNAs and other non-coding RNAs as targets for anticancer drug development. Nat Rev Drug Discov 12: 847-865, 2013.

5. Shen G, Li X, Jia YF, Plazza GA and Xi Y: Hypoxia-regulated microRNAs in human cancer. Acta Pharmacol Sin 34: 336-341, 2013.

6. Yu G, Jiang P, Xiang Y, Zhang Y, Zhu Z, Zhang C, Lee S, Lee W and Zhang Y: Increased expression of protease-activated receptor 4 and Trefoil factor 2 in human colorectal cancer. PLoS One 10: e0122678, 2015.

7. Sun S, Jiang P, Su W, Xiang Y, Li J, Zeng L and Yang S: Wild chrysanthemum extract prevents UVB radiation-induced acute cell death and photoaging. Cytotechnology 68: 229-240, 2016.

8. Moitra K, Im K, Limpert K, Borsa A, Sawitzke J, Robey R, Yuhki N, Savan R, Huang da W, Lempicki RA, et al: Differential gene and microRNA expression between etoposide resistant and etoposide sensitive MCF7 breast cancer cell lines. PLoS One 7: e45268, 2012.

9. Xiang Y, Gao Q, Su W, Zeng L, Wang J, Hu Y, Nie W, Ma X, Zhang Y, Lee W and Zhang Y: Establishment, characterization and immortalization of a fibroblast cell line from the Chinese red belly toad Bombina maxima skin. Cytotechnology 64: 95-105, 2012.

10. Wang YJ, Guo XL, Li SA, Zhao YQ, Liu ZC, Lee WH, Xiang Y and Zhang Y: Prohibitin is involved in the activated internalization and degradation of protease-activated receptor 1. Biochim Biophys Acta 1843: 1393-1401, 2014.

11. Xiang Y, Wang X, Yan C, Gao Q, Li SA, Liu J, Zhou K, Guo X, Lee $\mathrm{W}$ and Zhang Y: Adenosine-5'-triphosphate (ATP) protects mice against bacterial infection by activation of the NLRP3 inflammasome. PLoS One 8: e63759, 2013.

12. Liang Z, Bian X and Shim H: Inhibition of breast cancer metastasis with microRNA-302a by downregulation of CXCR4 expression. Breast Cancer Res Treat 146: 535-542, 2014.

13. Denoyelle C, Lambert B, Meryet-Figuière M, Vigneron N, Brotin E, Lecerf C, Abeilard E, Giffard F, Louis MH, Gauduchon P, et al: MiR-491-5p-induced apoptosis in ovarian carcinoma depends on the direct inhibition of both BCL-XL and EGFR leading to BIM activation. Cell Death Dis 5: e1445, 2014.

14. Zeng HL, Zhong Q, Qin YL, Bu QQ, Han XA, Jia HT and Liu HW: Hypoxia-mimetic agents inhibit proliferation and alter the morphology of human umbilical cord-derived mesenchymal stem cells. BMC Cell Biol 12: 32, 2011.

15. Dai ZJ, Gao J, Ma XB, Yan K, Liu XX, Kang HF, Ji ZZ, Guan HT and Wang XJ: Up-regulation of hypoxia inducible factor-1a by cobalt chloride correlates with proliferation and apoptosis in PC-2 cells. J Exp Clin Cancer Res 31: 28, 2012.

16. Yu X, Lu C, Liu H, Rao S, Cai J, Liu S, Kriegel AJ, Greene AS, Liang $M$ and Ding $X$ : Hypoxic preconditioning with cobalt of bone marrow mesenchymal stem cells improves cell migration and enhances therapy for treatment of ischemic acute kidney injury. PLoS One 8: e62703, 2013.

17. Li X, Liu Y, Granberg KJ, Wang Q, Moore LM, Ji P, Gumin J, Sulman EP, Calin GA, Haapasalo H, et al: Two mature products of MIR-491 coordinate to suppress key cancer hallmarks in glioblastoma. Oncogene 34: 1619-1628, 2015. 
18. Nakano H, Miyazawa T, Kinoshita K, Yamada Y and Yoshida T: Functional screening identifies a microRNA, miR-491 that induces apoptosis by targeting $\mathrm{Bcl}-\mathrm{X}(\mathrm{L})$ in colorectal cancer cells. Int J Cancer 127: 1072-1080, 2010.

19. Lan A, Liao X, Mo L, Yang C, Yang Z, Wang X, Hu F, Chen P, Feng J, Zheng D and Xiao L: Hydrogen sulfide protects against chemical hypoxia-induced injury by inhibiting ROS-activated ERK1/2 and p38MAPK signaling pathways in PC12 cells. PLoS One 6: e25921, 2011.

20. Huang WC, Chan SH, Jang TH, Chang JW, Ko YC, Yen TC, Chiang SL, Chiang WF, Shieh TY, Liao CT, et al: MiRNA-491-5p and GIT1 serve as modulators and biomarkers for oral squamous cell carcinoma invasion and metastasis. Cancer Res 74: 751-764, 2014.

21. Guo M, Song LP, Jiang Y, Liu W, Yu Y and Chen GQ: Hypoxia-mimetic agents desferrioxamine and cobalt chloride induce leukemic cell apoptosis through different hypoxia-inducible factor-1alpha independent mechanisms. Apoptosis 11: 67-77, 2006

22. Harris AL: Hypoxia--a key regulatory factor in tumour growth. Nat Rev Cancer 2: 38-47, 2002.

23. Gilkes DM, Semenza GL and Wirtz D: Hypoxia and the extracellular matrix: Drivers of tumour metastasis. Nat Rev Cancer 14: 430-439, 2014.

24. Chen CZ: MicroRNAs as oncogenes and tumor suppressors. New Engl J Med 353: 1768-1771, 2005.
25. Chatterjee S, Behnam Azad B and Nimmagadda S: The intricate role of CXCR4 in cancer. Adv Cancer Res 124: 31-82, 2014.

26. Balkwill F: Cancer and the chemokine network. Nat Rev Cancer 4: 540-550, 2004.

27. Schwab LP, Peacock DL, Majumdar D, Ingels JF, Jensen LC, Smith KD, Cushing RC and Seagroves TN: Hypoxia-inducible factor 1a promotes primary tumor growth and tumor-initiating cell activity in breast cancer. Breast Cancer Res 14: R6, 2012.

28. Marcus RE: The effect of low oxygen concentration on growth, glycolysis, and sulfate incorporation by articular chondrocytes in monolayer culture. Arthritis Rheum 16: 646-656, 1973.

29. Sharma GD, He J and Bazan HE: P38 and ERK $1 / 2$ coordinate cellular migration and proliferation in epithelial wound healing: Evidence of cross-talk activation between MAP kinase cascades. J Biol Chem 278: 21989-21997, 2003.

30. Lu Z and Xu S: ERK1/2 MAP kinases in cell survival and apoptosis. IUBMB Life 58: 621-631, 2006.

This work is licensed under a Creative Commons Attribution-NonCommercial-NoDerivatives 4.0 International (CC BY-NC-ND 4.0) License. 